\title{
Effect of early enteral nutrition on patients with digestive tract surgery: A meta-analysis of randomized controlled trials
}

\author{
XIAO-LIANG SHU ${ }^{1 *}, \mathrm{KAI} \mathrm{KANG}^{2 *}$, LI-JUAN GU ${ }^{1}$ and YONG-SHENG ZHANG ${ }^{3}$ \\ ${ }^{1}$ Department of Nutrition, Jinshan Hospital, Fudan University, Shanghai 201508; ${ }^{2}$ Tong Ji \\ University School of Medicine, Shanghai 200120; ${ }^{3}$ Department of Nutrition, The First Hospital \\ Affiliated to Guangxi Medical University, Nanning, Guangxi 530027, P.R. China
}

Received December 11, 2015; Accepted July 25, 2016

DOI: 10.3892/etm.2016.3559

\begin{abstract}
Postoperative early enteral nutrition (EEN) is useful for the effective recovery of patients that have undergone surgery. However, the feasibility and efficacy of EEN in patients with digestive tract surgery remain inconclusive. In the present meta-analysis, the PubMed, EMBASE, Web of Science, The Cochrane Library, China National Knowledge Infrastructure and VIP databases were searched to identify controlled trials of patients with and without EEN following digestive tract surgery between October, 1966 and December, 2014. Methodological quality assessment was carried out for each of the included studies. For estimation of the analysis indexes, relative risk (RR) was used as the effect size of the the categorical variable, while the weighted mean difference (MD) was used as the effect size of the continuous variable. The meta-analysis was conducted using RevMan 5.2 software. Eleven randomized controlled trials involving 1,095 patients were included in the meta-analysis. The results revealed that, EEN in patients with digestive tract surgery was more effective in decreasing the incidence of infectious $[R R=0.50,95 \%$ confidence interval $(\mathrm{CI}): 0.38,0.67 ; \mathrm{P}<0.01]$ and non-infectious complications ( $\mathrm{RR}=0.72,95 \% \mathrm{CI}$ : 0.43 , 1.22; $\mathrm{P}<0.05)$ and shortening the length of first bowel action $(\mathrm{MD}=-4.10,95 \% \mathrm{CI}:-5.38,-2.82 ; \mathrm{P}<0.05)$. It also had a significant influence on increasing the serum albumin $(\mathrm{MD}=2.87$, $95 \%$ CI: $1.03,4.71 ; \mathrm{P}<0.05)$ and serum prealbumin $(\mathrm{MD}=0.04$, $95 \%$ CI: $0.02,0.05 ; \mathrm{P}<0.05)$ levels. In conclusion, the results of the study have shown that EEN in patients with digestive tract surgery improved the nutritional status, reduced the risk of postoperative complications, shortened the length of hospital
\end{abstract}

Correspondence to: Dr Yong-Sheng Zhang, Department of Nutrition, The First Hospital Affiliated to Guangxi Medical University, 6 Shuangyong Road, Nanning, Guangxi 530027, P.R. China

E-mail: fnk724@163.com

*Contributed equally

Key words: early enteral nutrition, surgery, digestive tract, recovery, meta-analysis stay and promoted the functional recovery of the digestive system.

\section{Introduction}

Parenteral nutrition (PN) and enteral nutrition (EN) are two important supportive therapies for clinical surgical treatment. Early EN (EEN) should be preferred to total PN (TPN) whenever possible or at any point that the patient has a functioning gut (1-4).

Numerous studies showed that EEN had a positive influence on improving intestinal function and reducing the incidence of postoperative complications, especially for severe illness (5-7). Additionally, EEN has been demonstrated to be more physiological, to prevent morphologic and functional trauma-related alterations of the gut, to modulate the immune and inflammatory responses to injury, and to be more cost-efficient than TPN (8-12). However, the feasibility and efficacy of EEN in patients with digestive tract surgery has remained inconclusive.

Randomized controlled trials (RCTs) (13) suggested that the early resumption of oral intake does not decrease the duration of postoperative ileus or lead to a significantly increased rate of nasogastric tube reinsertion. Eckerwall et al found that the overall early complication rate was higher in EN than TPN in patients with predicted severe acute pancreatitis (14).

The present meta-analysis was performed to investigate RCTs in patients with and without EEN after digestive tract surgery to provide concrete clinical evidence for the feasibility and efficacy of EEN.

\section{Materials and methods}

Study selection. The databases PubMed (http://www.pubmed. com), EMBASE (http://www.embase.com), Web of Science (http://apps.webofknowledge.com), The Cochrane Library (http://www.thecochranelibrary.com), China National Knowledge Infrastructure (CNKI; http://www.cnki.net/) and VIP (http://www.cqvip.com/) were systematically searched for RCTs concerning the effect of EEN (using the key terms: 'early feeding', 'early postoperative feeding', 'early postoperative enteral nutrition', 'early postoperation oral feeding', 'immediate enteral nutrition', 'immediate postoperative feeding' 
and their variants) in patients with digestive tract surgery (using the key terms 'operation', 'gastrointestinal surgery', 'upper digestive tract', 'alimentary tract', 'gut', 'colorectal', 'colon', 'rectum', 'stomach', 'pancreas', 'duodenum', 'gastric', 'intestinal', 'gastrectomy', and 'enterectomy' and their variants). When multiple articles for a similar study were found, we considered only the most complete and recently published ones and supplemented the present meta-analysis, if necessary, with data from the most complete or updated publication. References from the extracted articles and reviews were also consulted to complete the data bank.

Studies were included for the present meta-analysis if they complied with the following inclusion criteria: i) RCTs with parallel controlled design; ii) patients underwent digestive tract surgery for reasons other than renal, cardiac or hepatic failure; iii) EEN was provided within one postoperative day in the treatment group; iv) biochemical indices (serum total protein, serum albumin and serum prealbumin), length of first bowel action, infectious and non-infectious complications and length of hospital stay; and v) supplementary data relevant to this meta-analysis were available. Studies were excluded from the present meta-analysis due to: i) patients not being randomized; ii) inadequate statistical analysis; and iii) use of animal trials, less relevant, review articles and case reports.

Data extraction. From each study, we extracted information regarding first author, year of publication, country of origin, sample size, age, gender, type of diseases or surgeries, average study follow-up time, type of intervention, duration of intervention, disease outcome, method of outcome ascertainment, unit of measurement and corresponding $95 \%$ confidence intervals (CIs), standard error (SEs), or exact P-values from text, and Tables and Figs. Since the differences in the study populations and study design of the included studies potentially cause variations in the results, a study-quality score was calculated using methodological quality assessment (15) for each of the included traits ranging from 0 to 5 . Based on this, the studies were categorized into high quality score (3-5 points), low quality score (1-2 points) and no RCTs (0 point).

Data analysis. The data pooling was performed following classical meta-analysis method using the Review Manager (RevMan) (Computer Program). (Version 5.2. Copenhagen: The Nordic Cochrane Centre, The Cochrane Collaboration 2014; http://ims.cochrane.org/revman/). P<0.05 was considered statistically significant. The missing standard deviation (SD) value for one trial was imputed from SD values of the remaining trials using the same measure (16). For estimation of the analysis indexes, relative risk (RR) was used as the effect size of the categorical variable, while the weighted mean difference (MD) was used as the effect size of the continuous variable. The $95 \%$ CI was calculated for each investigation and for each outcome variable. The statistical heterogeneity test was performed using the $\mathrm{I}^{2}$ statistic $(\alpha=0.05)$, which assessed the appropriateness of pooling the individual study results prior to calculating the standardized mean effect for all the trials. The $\mathrm{I}^{2}$ value provided an estimate of the amount of variance across studies because of heterogeneity rather than chance (17). The $\mathrm{I}^{2}$ values 25,50 and $75 \%$ corresponded to low, moderate and high levels of heterogeneity, respectively. If $\mathrm{P} \geq 0.05$, the

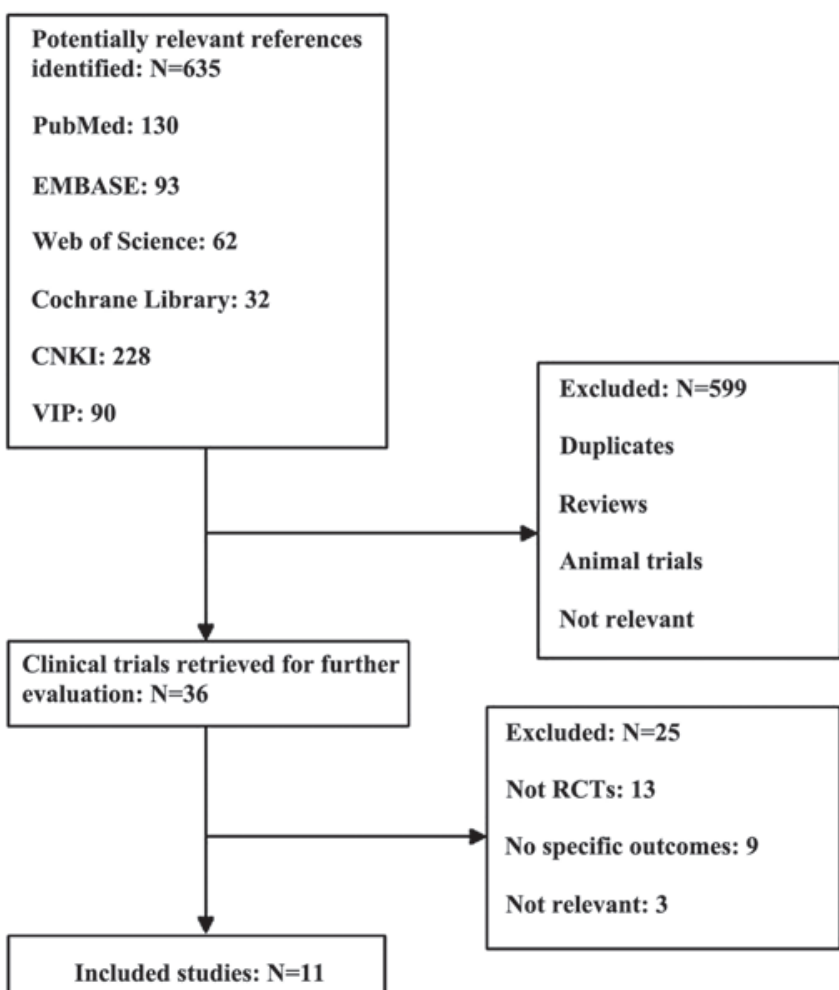

Figure 1. Flow chart showing the trial selection process for this study. RCT, randomized controlled trial; CNKI, China National Knowledge Infrastructure.

heterogeneity was not substantial and low between the trials. Thus, fixed-effects models were used with the Mantel-Haenszel (M-H) method weighting for combined statistics. If $\mathrm{P}<0.05$, the heterogeneity was considered substantial and high between the trials. Consequently, combined results were conducted using the random-effects models, which were inverse variance weighting or the DerSimonian-Laird method based on the fixed-effects models. A priori potential sources of heterogeneity were a concern for publication bias. The possible publication bias was investigated by drawing a funnel plot to search for funnel plot asymmetry and meta-regression based on study size (18).

\section{Results}

Characteristics of the studies. The initial search yielded 635 potentially relevant results and from these only $11(19,29)$ RCTs complied with the inclusion criteria and were subsequently included in the present meta-analysis (Fig. 1). A total of 1,095 samples were considered from these 11 RCTs and the sample size varied between studies ranging from 28 to 317 . Only the subjects who received EEN within one postoperative day constituted the treatment group for this meta-analysis. The information extracted from these RCTs is presented in Table I. The 11 RCTs were published during the period between October, 1966 to December, 2014.

\section{Relevant biochemical indices}

Serum total protein. In total, 126 participants from $3(24,26,28)$ of the 11 studies were enrolled to evaluate the change of serum total protein $(\mathrm{g} / \mathrm{l})$. Since the heterogeneity of serum between 


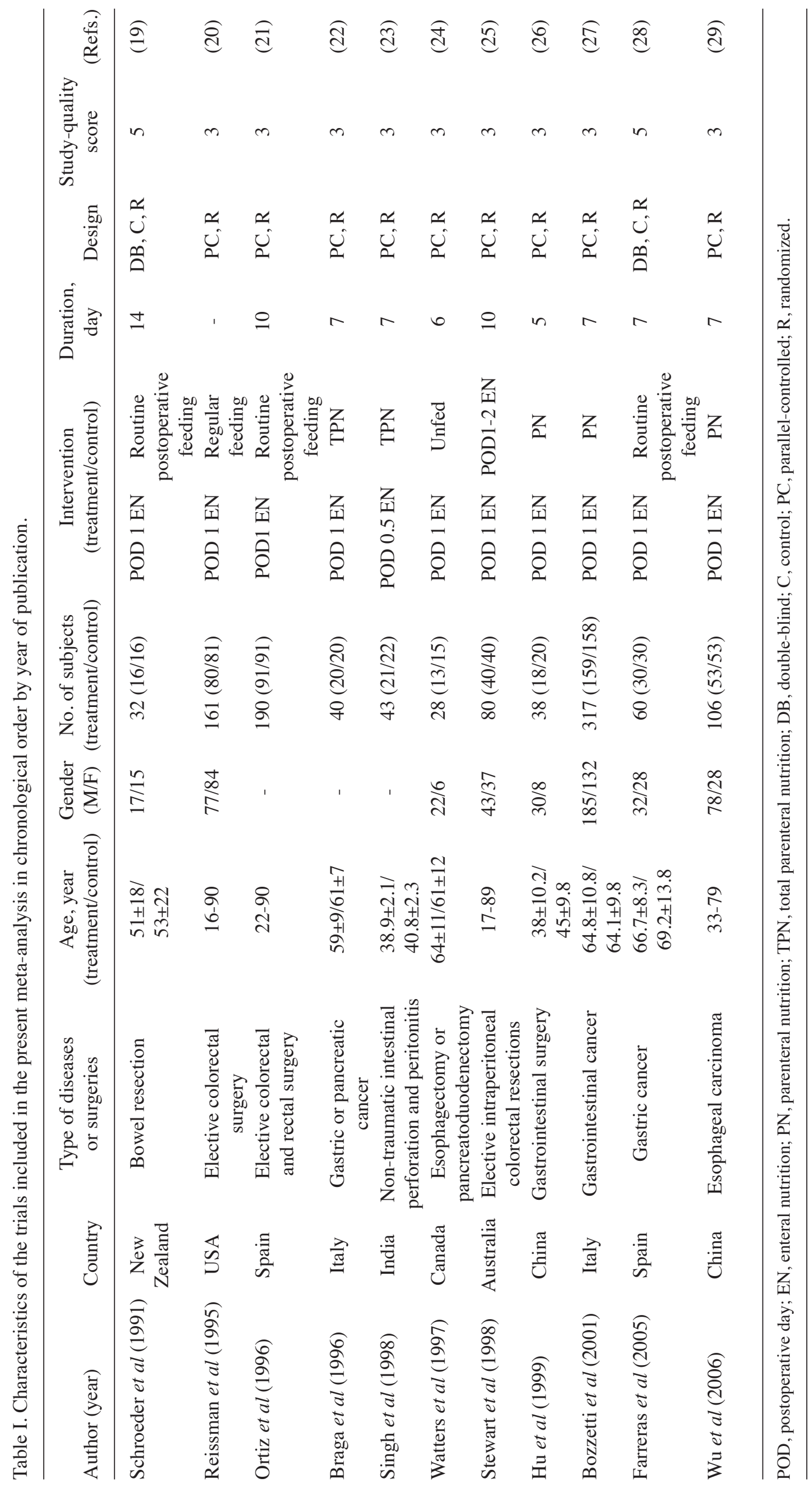




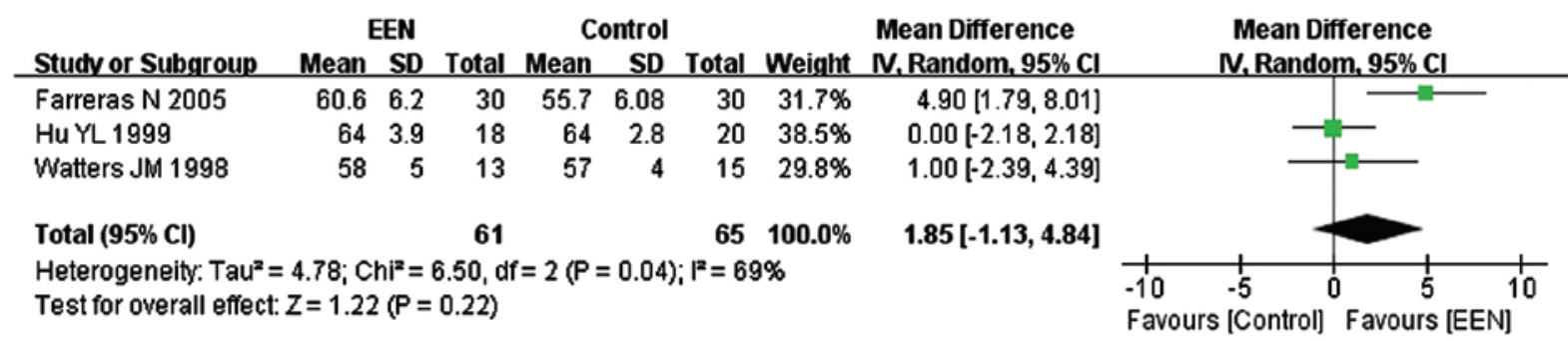

Figure 2. Serum total protein level in treatment [early enteral nutrition (EEN)] and control groups using the random-effects model. SD, standard deviation; CI, confidence interval.

\begin{tabular}{|c|c|c|c|c|c|c|c|c|c|c|}
\hline Study or Subgroup & \multicolumn{3}{|c|}{ EEN } & \multicolumn{3}{|c|}{ Control } & \multicolumn{2}{|r|}{$\begin{array}{l}\text { Mean Difference } \\
\text { N. Random, 95\% Cl }\end{array}$} & \multicolumn{2}{|c|}{$\begin{array}{c}\text { Mean Difference } \\
\text { N. Random, 95\% Cl }\end{array}$} \\
\hline Braga M 1996 & 39.4 & 4.7 & 20 & 32.9 & 3.7 & 20 & $18.2 \%$ & $6.50[3.88,9.12]$ & & 二 \\
\hline Farreras N 2005 & 26.7 & 5.9 & 30 & 24 & 4.8 & 30 & $17.7 \%$ & $2.70[-0.02,5.42]$ & & \\
\hline Hu YL 1999 & 40 & 4.2 & 18 & 41 & 3.7 & 20 & $18.7 \%$ & $-1.00[-3.53,1.53]$ & & \\
\hline Watters JM 1998 & 34 & 4 & 13 & 31 & 4 & 15 & $16.5 \%$ & $3.00[0.03,5.97]$ & & \\
\hline Wu PR 2006 & 38.5 & 0.7 & 53 & 35.4 & 0.5 & 53 & $28.8 \%$ & $3.10[2.87,3.33]$ & & ! \\
\hline Total $(95 \% \mathrm{Cl})$ & & & 134 & & & 138 & $100.0 \%$ & $2.87[1.03,4.71]$ & & \\
\hline \multicolumn{9}{|c|}{$\begin{array}{l}\text { Heterogeneity: } \mathrm{Tau}^{2}=3.04 ; \mathrm{Ch}^{2}=16.64, \mathrm{df}=4(P=0.002) ;\left.\right|^{2}=76 \% \\
\text { Test for overall effect: } Z=3.05(P=0.002)\end{array}$} & 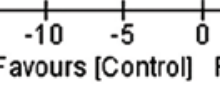 & $\begin{array}{c}5 \\
\text { Favours [EE }\end{array}$ \\
\hline
\end{tabular}

Figure 3. Forest plot of serum albumin level in the treatment [early enteral nutrition (EEN)] and control groups using the random-effects model. SD, standard deviation; CI, confidence interval.

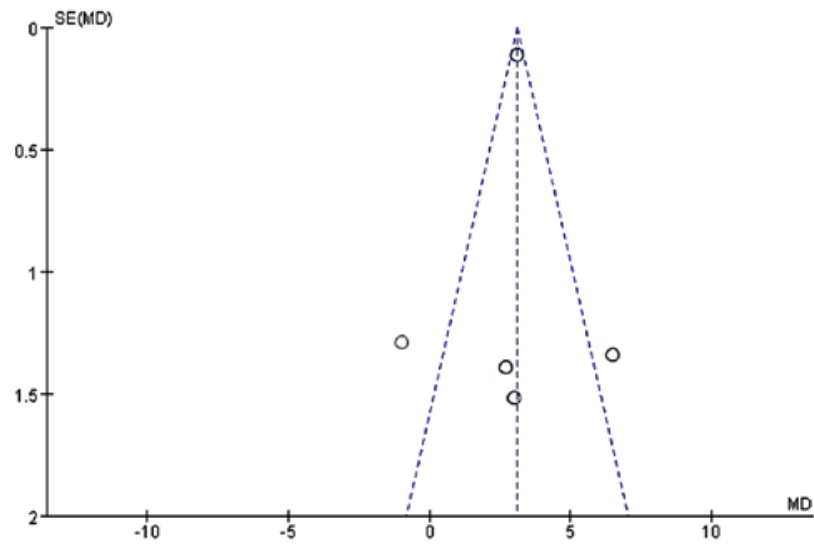

Figure 4. Funnel plot showing the change of serum albumin between the treatment (early enteral nutrition) and control groups. Dotted lines are pseudo $95 \%$ confidence intervals. SE, standard error; MD, mean difference.

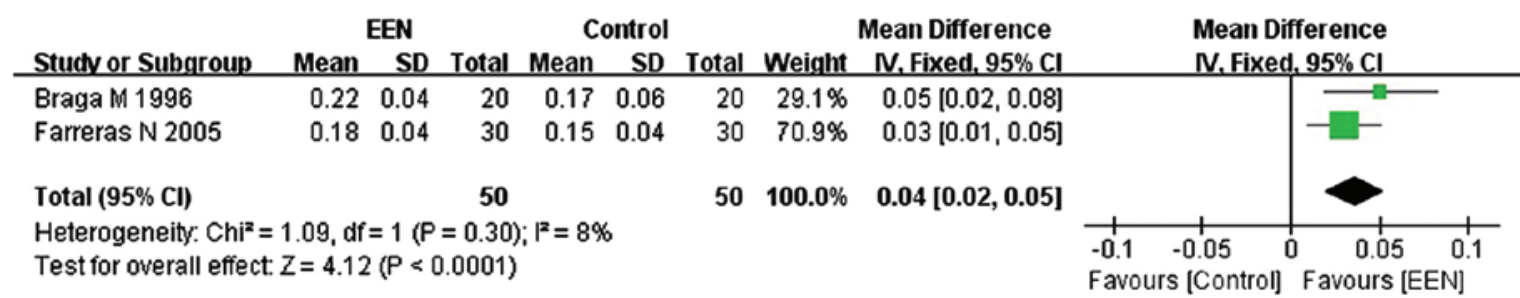

Figure 5. Forest plot of the change of serum albumin level between the treatment [early enteral nutrition (EEN)] and control groups using the fixed-effects model. M-H, Mantel-Haenszel test; SD, standard deviation; CI, confidence interval.

the studies was significant $\left(\mathrm{I}^{2}=69 \% ; \mathrm{P}<0.05 ; \chi^{2}=6.50\right)$ the random-effects model was used. From the analysis, we found statistically insignificant difference between the EEN and control group ( $\mathrm{MD}=1.85,95 \%$ CI: $-1.13,4.84 ; \mathrm{P}>0.05$ ) (Fig. 2).
Serum albumin. Approximately 272 participants from 5 of the 11 studies $(22,24,26,28,29)$ were enrolled to evaluate the serum albumin $(\mathrm{g} / \mathrm{l})$. Since, the heterogeneity of serum albumin between the studies was significant $\left(\mathrm{I}^{2}=76 \% ; \mathrm{P}<0.05\right.$; 


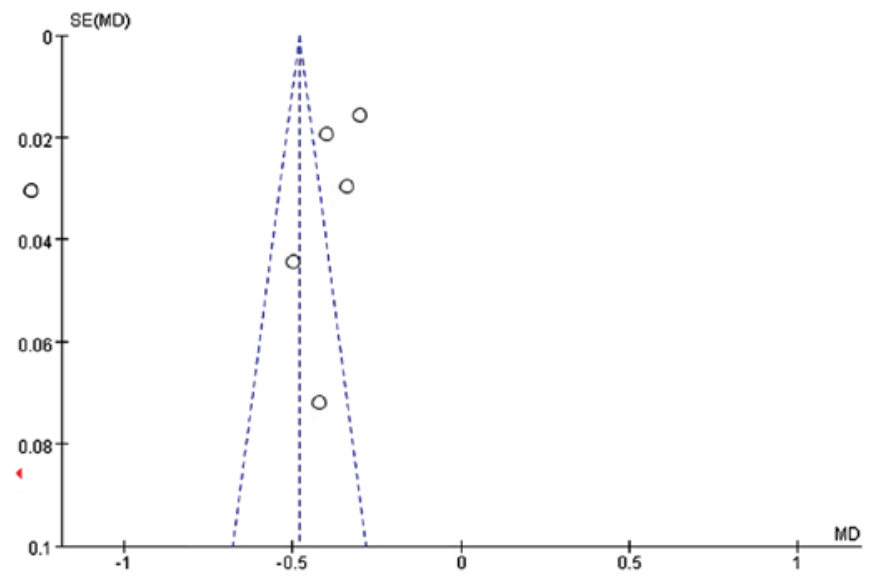

Figure 6. Funnel plot of studies showing the length of first bowel action in treatment (EEN) group and control group. Dotted lines are pseudo 95\% confidence intervals. SE, standard error; MD, mean difference.

\begin{tabular}{|c|c|c|c|c|c|c|c|c|c|c|c|}
\hline \multirow[b]{2}{*}{ Stucty or Subgroup } & \multicolumn{3}{|c|}{ EEN } & \multicolumn{3}{|c|}{ Control } & \multirow{2}{*}{\multicolumn{2}{|c|}{$\begin{array}{c}\text { Std. Mean Difference } \\
\text { Weight }\end{array}$}} & \multirow{2}{*}{\multicolumn{3}{|c|}{$\begin{array}{l}\text { Std. Mean Difference } \\
\text { IV. Random, } 95 \% \mathrm{Cl}\end{array}$}} \\
\hline & Mean & SD & Total & Mean & SD & Total & & & & & \\
\hline Bozzetti F 2001 & 2.34 & 0.22 & 159 & 2.68 & 0.3 & 158 & $16.2 \%$ & $-1.29[-1.53,-1.05]$ & $=$ & & \\
\hline Hu YL 1999 & 1.5 & 0.15 & 18 & 1.92 & 0.28 & 20 & $15.4 \%$ & $-1.80[-2.57,-1.04]$ & $=$ & & \\
\hline Ortiz H 1995 & 4.3 & 0.12 & 91 & 4.7 & 0.14 & 91 & $16.0 \%$ & $-3.06[-3.49,-2.62]$ & $=$ & & \\
\hline Reissman P 1995 & 3.8 & 0.1 & 80 & 4.1 & 0.1 & 81 & $15.9 \%$ & $-2.99[-3.44,-2.53]$ & * & & \\
\hline Schroeder D 1991 & 2.42 & 0.13 & 16 & 2.92 & 0.12 & 16 & $14.1 \%$ & $-3.90[-5.13,-2.66]$ & $\rightarrow$ & & \\
\hline Stewart BT 1998 & 3.23 & 0.15 & 40 & 4.51 & 0.12 & 40 & $13.1 \%$ & $-9.33[-10.88,-7.79]$ & $\because$ & & \\
\hline Watters JM 1998 & 2.39 & 0.11 & 13 & 4.7 & 0.31 & 15 & $9.3 \%$ & $-9.37[-12.12,-6.62]$ & & & \\
\hline Total (95\% Cl) & & & 417 & & & 421 & $100.0 \%$ & $-4.10[-5.38,-2.82]$ & & & \\
\hline $\begin{array}{l}\text { Heterogeneity: } \mathrm{Tau}^{2}= \\
\text { Test for overall effect }\end{array}$ & $\begin{array}{l}2.64 ; C \\
Z=6.26\end{array}$ & $\begin{array}{l}h i^{2}=1 \\
\langle P<C\end{array}$ & $\begin{array}{l}6.21, c \\
.00001\end{array}$ & $d f=6($ & $<<0.00$ & & $\left.\right|^{2}=97 \%$ & & $\begin{array}{ll}-10 & -5 \\
\text { Favours [Control] }\end{array}$ & $\begin{array}{lc}0 & 5 \\
\text { Favours }\end{array}$ & $\begin{array}{l}10 \\
{[N]}\end{array}$ \\
\hline
\end{tabular}

Figure 7. Forest plot showing change of length of first bowel action between treatment [early enteral nutrition (EEN)] group and control group: Random-effects model. SD, standard deviation; $\mathrm{CI}$, confidence interval.

$\left.\chi^{2}=16.64\right)$ we applied the random-effects model. We found a statistically significant difference between the EEN and control groups ( $\mathrm{MD}=2.87,95 \%$ CI: 1.03, 4.71; $\mathrm{P}<0.05$ ) (Fig. 3). The symmetry funnel plot suggested scarcely any publication bias existed between studies mentioning change of serum albumin (Fig. 4).

Serum prealbumin. Of the 11 studies, only $2(22,28)$ studies with a sample size of 100 subjects focused on serum prealbumin $(\mathrm{g} / \mathrm{l})$. The fixed-effects model was used for the heterogeneity to be considered acceptable $\left(\mathrm{I}^{2}=8 \% ; \mathrm{P}>0.05 ; \chi^{2}=1.09\right)$. Our analysis revealed that providing EEN was more effective in increasing the serum prealbumin $(\mathrm{MD}=0.04,95 \% \mathrm{CI}: 0.02$, $0.05 ; \mathrm{P}<0.05)$ than the control (Fig. 5).

Length of first bowel action. Information was obtained on the length of first bowel action in 838 patients from 7 studies $(19-21,24-27)$. Since the heterogeneity was significant $\left(\mathrm{I}^{2}=97 \% ; \mathrm{P}<0.05 ; \chi^{2}=196.21\right)$ (Fig. 7$)$ and the asymmetry funnel plot suggested possible publication bias existed between these (Fig. 6), we applied the random-effects model to analyze the data. Our analysis revealed that the patients in the EEN group had a shorter length of first bowel action than the control group ( $\mathrm{MD}=-4.10,95 \%$ CI: -5.38, -2.82; $\mathrm{P}<0.05$ ) (Fig. 7).

Complications. In 8 studies (19-21,23,25,27-29) analysed, it was found that EEN had an impact on postoperative complications
Table II. Classification of complications in the included trials.

\begin{tabular}{cll}
\hline S1., no. & \multicolumn{1}{c}{$\begin{array}{c}\text { Infectious } \\
\text { complications }\end{array}$} & \multicolumn{1}{c}{$\begin{array}{c}\text { Non-infectious } \\
\text { complications }\end{array}$} \\
\hline 1 & Bacteraemia & Anastomotic leak \\
2 & Intra-abdominal abscess & Gastrointestinal bleeding \\
3 & Pelvic abscess & Hemoperitoneum \\
4 & Pneumonia & Hepatic dysfunction \\
5 & Sepsis & Ileus/intestinal obstruction \\
6 & Septic shock & Myocardial infarction \\
7 & Septic coagulopathy & Pancreatic fistula \\
8 & Urinary tract infections & Pancreatitis \\
9 & Wound infections & Pericarditis \\
10 & & Pleural effusion \\
11 & & Suture failure \\
12 & & Renal failure \\
13 & & Respiratory failure \\
14 & & Venous thrombosis \\
15 & & Wound dehiscence \\
\hline
\end{tabular}

(infectious and non-infectious complications) (Table II) in 981 patients with digestive tract surgery. 


\begin{tabular}{|c|c|c|c|c|c|c|c|c|}
\hline Stucty or Subgroup & $\begin{array}{l}\text { EEN } \\
\text { Events }\end{array}$ & Total & $\begin{array}{c}\text { Contr } \\
\text { Events }\end{array}$ & $\begin{array}{l}\text { ol } \\
\text { Total }\end{array}$ & Weight & $\begin{array}{c}\text { Risk Ratio } \\
\text { M-H, Fixed, 95\% Cl }\end{array}$ & $\begin{array}{r}\text { Risk } \\
\text { M-H, Fixe }\end{array}$ & $\begin{array}{l}\text { Ratio } \\
\text { ed, } 95 \% \mathrm{Cl}\end{array}$ \\
\hline Bozzetti F 2001 & 25 & 159 & 42 & 158 & $39.2 \%$ & $0.59[0.38,0.92]$ & - & \\
\hline Farreras N 2005 & 2 & 30 & 9 & 30 & $8.4 \%$ & $0.22[0.05,0.94]$ & & \\
\hline Ortiz H 1996 & 8 & 91 & 9 & 91 & $8.4 \%$ & $0.89[0.36,2.20]$ & & \\
\hline Reissman P 1995 & 5 & 80 & 4 & 81 & $3.7 \%$ & $1.27[0.35,4.54]$ & & \\
\hline Schroeder D 1991 & 1 & 16 & 0 & 16 & $0.5 \%$ & $3.00[0.13,68.57]$ & & \\
\hline Singh G 1998 & 8 & 21 & 22 & 22 & $20.4 \%$ & $0.39[0.23,0.67]$ & $\rightarrow-$ & \\
\hline Stewart BT 1998 & 1 & 40 & 6 & 40 & $5.6 \%$ & $0.17[0.02,1.32]$ & & \\
\hline Wu PR 2006 & 3 & 53 & 15 & 53 & $13.9 \%$ & $0.20[0.06,0.65]$ & & \\
\hline Total $(95 \% \mathrm{Cl})$ & & 490 & & 491 & $100.0 \%$ & $0.50[0.38,0.67]$ & & \\
\hline Total events & 53 & & 107 & & & & & \\
\hline \multicolumn{7}{|c|}{$\begin{array}{l}\text { Heterogeneity: } \mathrm{Chi}^{2}=10.75, \mathrm{df}=7(\mathrm{P}=0.15) ; \mathrm{F}^{\mathrm{F}}=35 \% \\
\text { Test for overall effect: } Z=4.66(P<0.00001)\end{array}$} & $\begin{array}{l}0.010 .1 \\
\text { Favours [EEN] }\end{array}$ & $\begin{array}{llr}1 & 10 & 100 \\
\text { ] Favours [Control] }\end{array}$ \\
\hline
\end{tabular}

Figure 8. Forest plot of the infectious complications between the treatment [early enteral nutrition (EEN)] and control groups using the fixed-effects model. M-H, Mantel-Haenszel test; SD, standard deviation; CI, confidence interval.

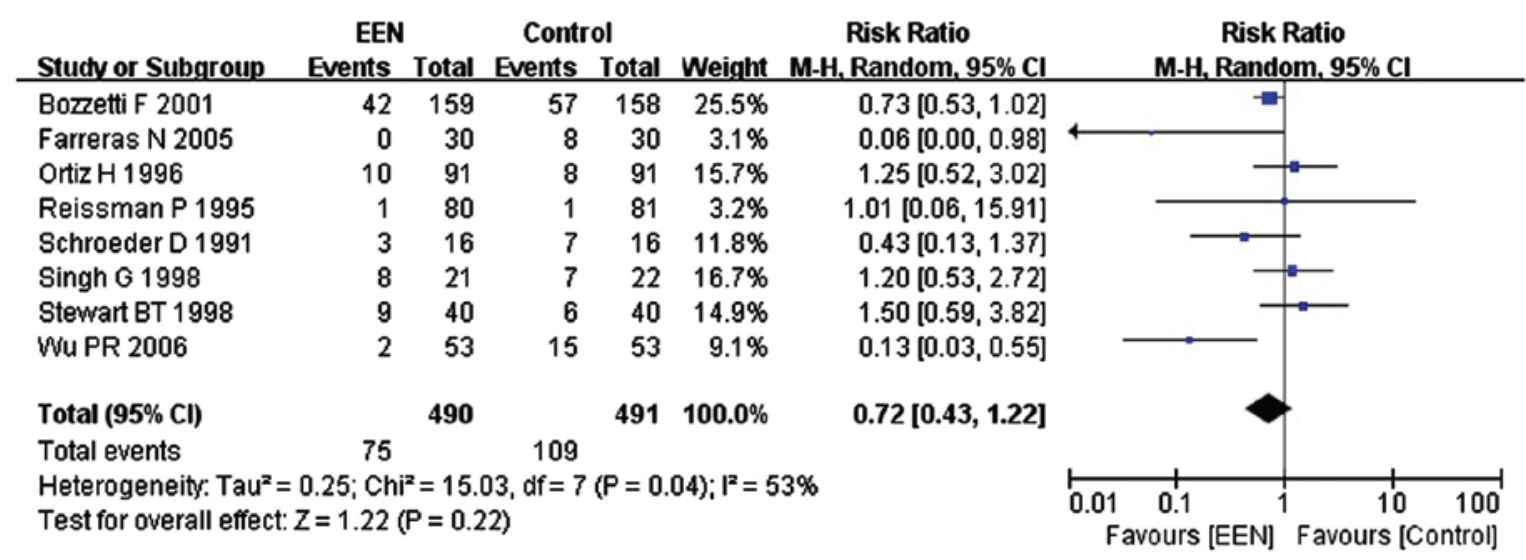

Figure 9. Forest plot of the non-infectious complications between the treatment [early enteral nutrition (EEN)] and control groups using the fixed-effects model. M-H: Mantel-Haenszel test; SD, standard deviation; CI, confidence interval.

Infectious complications. Our analysis using the fixed-effect model for infectious complications $\left(\mathrm{I}^{2}=35 \% ; \mathrm{P}>0.05 ; \chi^{2}=10.75\right)$ suggested that, EEN was more effective in decreasing the incidence of infectious complications in comparison with control $(\mathrm{RR}=0.50,95 \%$ CI: 0.38, 0.67; P<0.01) (Fig. 8).

Non-infectious complications. Our analysis revealed that the heterogeneity of non-infectious complications between the studies was significant $\left(\mathrm{I}^{2}=53 \% ; \mathrm{P}<0.05 ; \chi^{2}=15.03\right)$. Thus, we performed a subgroup analysis and the subgroups were divided dependent on whether the EN or PN were added to the control group. $\mathrm{I}^{2}$ between the subgroups was $0 \%\left(\mathrm{P}=0.60 ; \mathrm{Chi}^{2}=0.28\right)$. Consequently, the fixed-effects model was used. The results suggested that patients in the EEN group had a lower incidence of non-infectious complication ( $\mathrm{RR}=0.72,95 \% \mathrm{CI}$ : $0.43,1.22$; $\mathrm{P}<0.05)$ than the control (Fig. 9).

Length of hospital stay. Five studies $(20,23,24,26,27)$ comprising 587 subjects mentioned the length of hospital stay (day). $\mathrm{I}^{2}$ between the studies was $76 \%\left(\mathrm{P}<0.05 ; \chi^{2}=16.67\right)$ and thus a random-effects model was used. Our analysis revealed no significant difference with respect to shortening the length of hospital stay between the EEN and control groupa $(\mathrm{MD}=-0.50,95 \% \mathrm{CI}:-1.56,0.56 ; \mathrm{P}>0.05)$ (Fig. 10).
Furthermore, the asymmetry funnel plot suggested a possible publication bias existed between the studies in which patients mentioned the change of length of hospital stay (Fig. 11).

\section{Discussion}

Nutritional support is a vital part of the therapy of most surgical patients. Early initiation, particularly via the enteral route has a significant effect on postoperative recovery in a wide variety of patients (30). However, the physiological mechanisms underlying the beneficial effect of EEN have yet to be fully elucidated. Factors that may play a role include preservation of gut mass, prevention of increased gut permeability to bacteria and other toxins, and maintenance of the gut-associated lymphoid tissue (31). Classically, the term 'early' was defined as EN administration within postoperative day 3 (32); however, 'early' has been more recently redefined as EN administration within 24-48 $\mathrm{h}$ after admission or surgery (33). It appears that administration of nutrition within $24 \mathrm{~h}$ of major surgery, injury, or burn is ideal, but within $48 \mathrm{~h}$ is acceptable. However, hemodynamic stability is a prerequisite to the initiation of enteral feeding (34). RCTs included in the present meta-analysis administered EN support to patients within 12 or $24 \mathrm{~h}$ after digestive tract surgery. 


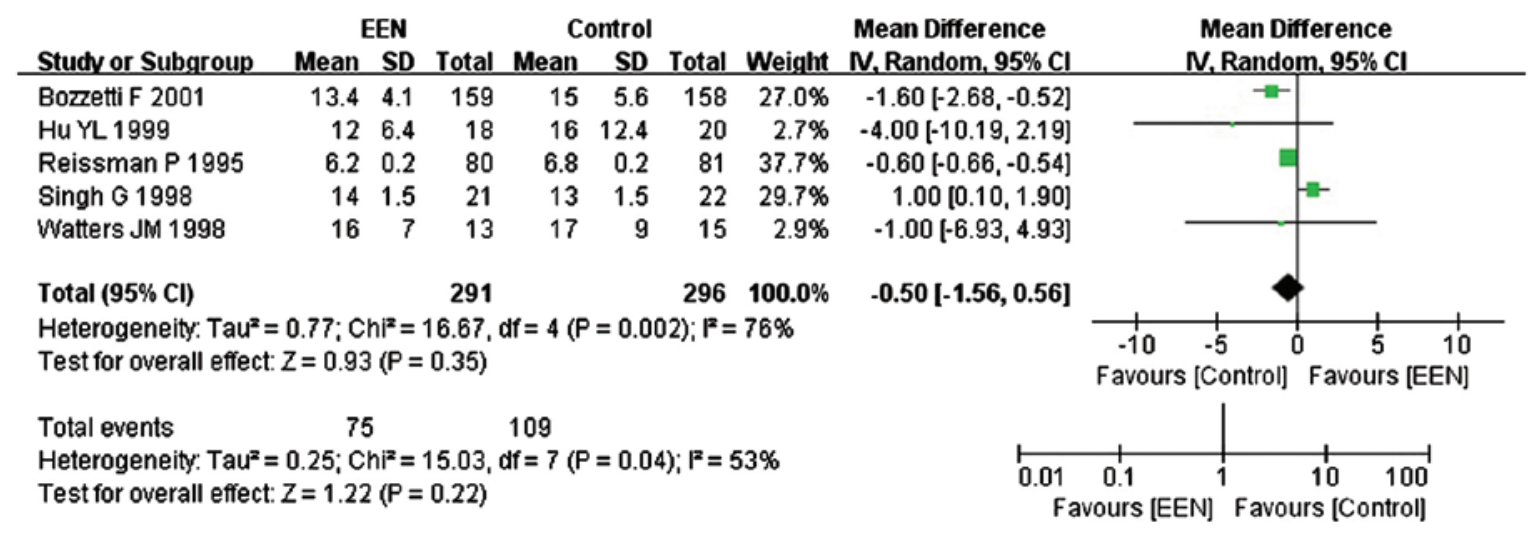

Figure 10. Forest plot of the length of hospital stay between treatment [early enteral nutrition (EEN)] group and control group: random-effects model. SD, standard deviation; CI, confidence interval.

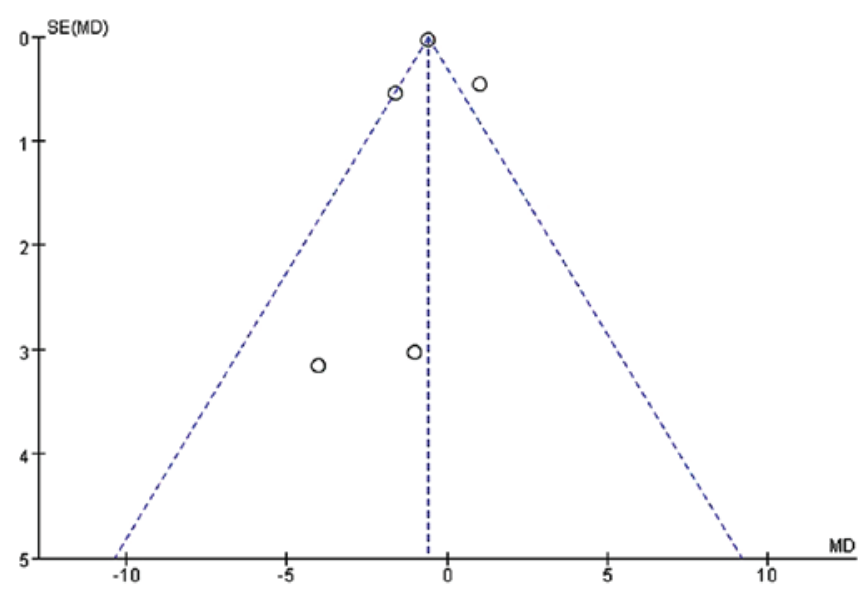

Figure 11. Funnel plot of studies mentioning the length of hospital stay between treatment (early enteral nutrition) group and control group. Dotted lines are pseudo $95 \%$ confidence intervals. SE, standard error; MD, mean difference.

Surgical patients usually present an intense metabolic state due to neuroendocrine stress, which may exacerbate protein catabolism developing negative nitrogen balance (35). Serum protein is an important indicator of the body's nutritional status. Serum albumin is the most abundant protein in blood plasma with a serum half-life of approximately 20 days, serving as a potential marker for nutritional status (36). The serum half-life of prealbumin is approximately 1.9 days, constituting it a sensitive marker of nutritional evaluation for a short period of time (37). In the present meta-analysis, although the administration of EEN had no significant effect on serum total protein, it significantly increased the levels of serum albumin and prealbumin, suggesting use of EEN benefited protein synthesis and wound healing, thereby improving the nutritional status of patients.

Previous findings have shown that PN induced an atrophy of the small intestinal mucosa due to a strong reduction in villi height and the crypt length, resulting in intestinal barrier dysfunction $(38,39)$. Therefore, $\mathrm{PN}$ often induced enterogenic infection in patients with digestive tract surgery. EN support had fewer infectious complications than others by comparison. The rationale of nil by mouth and gastric decompression aims to prevent postoperative nausea and vomiting and protect anastomosis, thus allowing wound healing to occur prior to the body experiencing stress from food (40). Our meta-analysis revealed that EEN for patients with digestive tract surgery decreased the incidence of postoperative infectious and non-infectious complications effectively, suggesting EEN is important in protecting the intestinal barrier, improving immune function and reducing the incidence of postoperative infections. In addition, EEN administration for patients with digestive tract surgery resulted in shorter length of first bowel action after surgery. Thus, EEN may stimulate the growth of intestinal epithelial cells, regulate the neuroendocrine system and induce gut hormone secretion, and subsequently increased blood flow to vital organs of the digestive system for functional recovery (41-43). Furthermore, fiber in the EN may have also contributed to the gastrointestinal recovery after surgery (44). As for the length of hospital stay, the analysis showed no significant difference between the EEN and control groups.

The present meta-analysis has some limitations. First, the 11 included trials mentioned randomization and parallel control, but did not mention whether the studies were blinded, which affects the quality scores of the included trials. Second, the quality score of Bozzetti et al (27) was 3, but the number of enrolled subjects was large, which leads to uncertainty in biases to the final result of the present meta-analysis. Third, 
the variety of intervention in the control group and duration of nutrition support between the included trials may also affect the final results.

In conclusion, the results show that EEN for patients with digestive tract surgery improves the nutritional status, promotes the functional recovery of digestive system and reduces the risk of postoperative complications.

\section{Acknowledgements}

The present study was supported by the 'Twelfth Five-Year' National Key Technology R\&D Program of China (grant no. 2012BAI35B03).

\section{References}

1. Klein S, Kinney J, Jeejeebhoy K, Alpers D, Hellerstein M, Murray M and Twomey P: Nutrition support in clinical practice: Review of published data and recommendations for future research directions. National Institutes of Health, American Society for Parenteral and Enteral Nutrition, and American Society for Clinical Nutrition. JPEN J Parenter Enteral Nutr 21: 133-156, 1997.

2. American Gastroenterological Association Medical Position Statement: Guidelines for the use of enteral nutrition. Gastroenterology 108: 1280-1281, 1995.

3. Chambrier C and Sztark F; Société Francophone de nutrition clinique et métabolisme (SFNEP); Société française d'anesthésie et réanimation (SFAR): French clinical guidelines on perioperative nutrition. Update of the 1994 consensus conference on perioperative artificial nutrition for elective surgery in adults J Visc Surg 149: e325-e336, 2012.

4. Pironi L, Candusso M, Biondo A, Bosco A, Castaldi P, Contaldo F, Finocchiaro E, Giannoni A, Mazzuoli S, Orlandoni P, et al; Italian Society for Parenteral and Enteral Nutrition Executive Committee: Prevalence of home artificial nutrition in Italy in 2005: A survey by the Italian Society for Parenteral and Enteral Nutrition (SINPE). Clin Nutr 26: 123-132, 2007.

5. Kaur N, Gupta MK and Minocha VR: Early enteral feeding by nasoenteric tubes in patients with perforation peritonitis. World J Surg 29: 1023-1027, discussion 1027-1028, 2005.

6. Grizas S, Gulbinas A, Barauskas G and Pundzius J: A comparison of the effectiveness of the early enteral and natural nutrition after pancreatoduodenectomy. Medicina (Kaunas) 44: 678-686, 2008.

7. Zhang K, Sun WB, Wang HF, Li ZW, Zhang XD, Wang HB and Ji X: Early enteral and parenteral nutritional support in patients with cirrhotic portal hypertension after pericardial devascularization. Hepatobiliary Pancreat Dis Int 4: 55-59, 2005.

8. Gianotti L, Alexander JW, Nelson JL, Fukushima R, Pyles T and Chalk CL: Role of early enteral feeding and acute starvation on postburn bacterial translocation and host defense: Prospective, randomized trials. Crit Care Med 22: 265-272, 1994.

9. Johnson CD and Kudsk KA: Nutrition and intestinal mucosal immunity. Clin Nutr 18: 337-344, 1999.

10. Braga M, Gianotti L, Gentilini O, Parisi V, Salis C and Di Carlo V: Early postoperative enteral nutrition improves gut oxygenation and reduces costs compared with total parenteral nutrition. Crit Care Med 29: 242-248, 2001.

11. Cunningham-Rundles S and Lin DH: Nutrition and the immune system of the gut. Nutrition 14: 573-579, 1998.

12. Lin MT, Saito H, Fukushima R, Inaba T, Fukatsu K, Inoue T, Furukawa S, Han I and Muto T: Route of nutritional supply influences local, systemic, and remote organ responses to intraperitoneal bacterial challenge. Ann Surg 223: 84-93, 1996.

13. Han-Geurts IJ, Hop WC, Kok NF, Lim A, Brouwer KJ and Jeekel J: Randomized clinical trial of the impact of early enteral feeding on postoperative ileus and recovery. Br J Surg 94: 555-561, 2007.

14. Eckerwall GE, Axelsson JB and Andersson RG: Early nasogastric feeding in predicted severe acute pancreatitis: A clinical, randomized study. Ann Surg 244: 959-965, discussion 965-967, 2006.
15. Jadad AR, Moore RA, Carroll D, Jenkinson C, Reynolds DJM, Gavaghan DJ and McQuay HJ: Assessing the quality of reports of randomized clinical trials: Is blinding necessary? Control Clin Trials 17: 1-12, 1996

16. Furukawa TA,Barbui C,Cipriani A, Brambilla P and Watanabe N: Imputing missing standard deviations in meta-analyses can provide accurate results. J Clin Epidemiol 59: 7-10, 2006.

17. Sofi F, Abbate R, Gensini GF and Casini A: Accruing evidence on benefits of adherence to the Mediterranean diet on health: An updated systematic review and meta-analysis. Am J Clin Nutr 92: 1189-1196, 2010

18. Sterne JAC, Egger M and Smith GD: Systematic reviews in health care: Investigating and dealing with publication and other biases in meta-analysis. BMJ 323: 101-105, 2001.

19. Schroeder D, Gillanders L, Mahr K and Hill GL: Effects of immediate postoperative enteral nutrition on body composition, muscle function, and wound healing. JPEN J Parenter Enteral Nutr 15: 376-383, 1991.

20. Reissman P, Teoh TA, Cohen SM, Weiss EG, Nogueras JJ and Wexner SD: Is early oral feeding safe after elective colorectal surgery? A prospective randomized trial. Ann Surg 222: 73-77, 1995.

21. Ortiz H, Armendariz P and Yarnoz C: Early postoperative feeding after elective colorectal surgery is not a benefit unique to laparoscopy-assisted procedures. Int J Colorectal Dis 11: 246-249, 1996.

22. Braga M, Vignali A, Gianotti L, Cestari A, Profili M and Carlo VD: Immune and nutritional effects of early enteral nutrition after major abdominal operations. Eur J Surg 162: 105-112, 1996.

23. Singh G, Ram RP and Khanna SK: Early postoperative enteral feeding in patients with nontraumatic intestinal perforation and peritonitis. J Am Coll Surg 187: 142-146, 1998.

24. Watters JM, Kirkpatrick SM, Norris SB, Shamji FM and Wells GA: Immediate postoperative enteral feeding results in impaired respiratory mechanics and decreased mobility. Ann Surg 226: 369-377, discussion 377-380, 1997.

25. Stewart BT, Woods RJ, Collopy BT, Fink RJ, Mackay JR and Keck JO: Early feeding after elective open colorectal resections: A prospective randomized trial. Aust N Z J Surg 68: 125-128, 1998.

26. Hu YL, Xiao XM, Yang CY and Xia HS: Early enteral nutrition after gastrointestinal surgery clinical research. J Clin Surg 7: 14-16, 1999.

27. Bozzetti F, Braga M, Gianotti L, Gavazzi C and Mariani L: Postoperative enteral versus parenteral nutrition in malnourished patients with gastrointestinal cancer: A randomised multicentre trial. Lancet 358: 1487-1492, 2001.

28. Farreras N, Artigas V, Cardona D, Rius X, Trias M and González JA: Effect of early postoperative enteral immunonutrition on wound healing in patients undergoing surgery for gastric cancer. Clin Nutr 24: 55-65, 2005.

29. Wu PR, Xu L and Zhang ZM: Comparative study of postoperative early enteral nutrition and parenteral nutrition in esophageal carcinoma. Zhonghua Wei Chang Wai Ke Za Zhi 9: 320-322, 2006 (In Chinese).

30. Minard G and Kudsk KA: Is early feeding beneficial? How early is early? New Horiz 2: 156-163, 1994.

31. Kobayashi K, Koyama Y, Kosugi S, Ishikawa T, Sakamoto K, Ichikawa $\mathrm{H}$ and Wakai $\mathrm{T}$ : Is early enteral nutrition better for postoperative course in esophageal cancer patients? Nutrients 5: 3461-3469, 2013.

32. Garrel DR, Davignon I and Lopez D: Length of care in patients with severe burns with or without early enteral nutritional support. A retrospective study. J Burn Care Rehabil 12: 85-90, 1991.

33. Doig GS, Heighes PT, Simpson F, Sweetman EA and Davies AR: Early enteral nutrition, provided within $24 \mathrm{~h}$ of injury or intensive care unit admission, significantly reduces mortality in critically ill patients: A meta-analysis of randomised controlled trials. Intensive Care Med 35: 2018-2027, 2009.

34. Serón-Arbeloa C, Puzo-Foncillas J, Garcés-Gimenez T, Escós-Orta J, Labarta-Monzón L and Lander-Azcona A: A retrospective study about the influence of early nutritional support on mortality and nosocomial infection in the critical care setting. Clin Nutr 30: 346-350, 2011.

35. Japur CC, Monteiro JP, Marchini JS, Garcia RW and Basile-Filho A: Can an adequate energy intake be able to reverse the negative nitrogen balance in mechanically ventilated critically ill patients? J Crit Care 25: 445-450, 2010. 
36. Roberts I, Blackhall K, Alderson P, Bunn F and Schierhout G: Human albumin solution for resuscitation and volume expansion in critically ill patients. Cochrane Database Syst Rev 9: CD001208, 2011.

37. Bae HJ, Lee HJ, Han DS, Suh YS, Lee YH, Lee HS, Cho JJ, Kong SH and Yang HK: Prealbumin levels as a useful marker for predicting infectious complications after gastric surgery. J Gastrointest Surg 15: 2136-2144, 2011

38. Groos S, Hunefeld G and Luciano L: Parenteral versus enteral nutrition: Morphological changes in human adult intestinal mucosa. J Submicrosc Cytol Pathol 28: 61-74, 1996.

39. Duran B: The effects of long-term total parenteral nutrition on gut mucosal immunity in children with short bowel syndrome: a systematic review. BMC Nurs 4: 2, 2005.

40. Silk DB and Gow NM: Postoperative starvation after gastrointestinal surgery. Early feeding is beneficial. BMJ 323: 761-762, 2001.
41. Cummings DE and Overduin J: Gastrointestinal regulation of food intake. J Clin Invest 117: 13-23, 2007.

42. Chapman MJ, Nguyen NQ and Deane AM: Gastrointestinal dysmotility: Evidence and clinical management. Curr Opin Clin Nutr Metab Care 16: 209-216, 2013.

43. Go VL, Srihari P and Kamerman Burns LA: Nutrition and gastroenteropancreatic neuroendocrine tumors. Endocrinol Metab Clin North Am 39: 827-837, 2010.

44. Van Ooteghem G, El-Mourad M, Slimani A, Margos W, El Nawar A, Patris A, Gallez JF, Kirsch J, Hauters P, Vallot F, et al: Is early enteral nutrition dangerous in acute non surgical complicated diverticulitis? About 25 patients fed with oral fiber free energetic liquid diet. Acta Gastroenterol Belg 76: 235-240, 2013. 